\title{
Very unusual giant pseudoaneurysm from insertion site of modified blalock-taussig shunt diagnosed by cardiac computed tomography: A case report
}

\author{
Sheba John ${ }^{1}$, Nitin Wadhwa ${ }^{2}$ and Dilachew Adebo ${ }^{1 *}$ \\ ${ }^{1}$ Department of Pediatrics, Division of Pediatric Cardiology, University of Texas Health Science Center at Houston, USA \\ ${ }^{2}$ Department of Pediatrics, Division of Pediatric Anesthesia, University of Texas Health Science Center at Houston, USA
}

\begin{abstract}
We report such extremely rare case of giant pseudoaneurysm which arises from insertion site of modified Blalock Taussig shunt which was diagnosed by cardiac computed tomography and managed conservatively.
\end{abstract}

\section{Case report}

A child with history of tricuspid valve atresia, ventricular septal defect and interrupted aortic arch who underwent initial single ventricle palliation with Norwood procedure, modified Blalock Taussig (BT) shunt placement, and aortic arch repair at age of 11 days. His course was complicated by concerning finding for aneurysm on routine follow up echocardiogram. He had cardiac computed tomography (CT) imaging at age of 2 months. The cardiac CT showed giant aneurysm in the region of modified Blalock Taussig shunt that extends to anterior mediastinum (Figures 1-3). The patient was managed conservatively. At the time of the second palliative surgery, bidirectional Glenn procedure, at age of 7 months, the fibrosed tissue of pseudoaneurysm was resected. Subsequently the patient underwent fenestrated fontan procedure without any complication at age of 3 years and 9 months. He did well after his Fontan procedure.

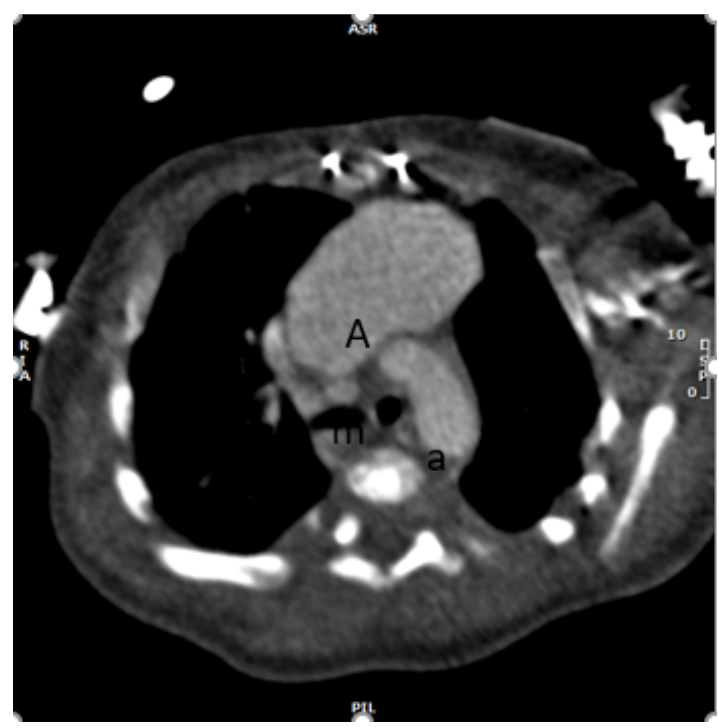

Figure 1A. Cardiac CT reconstructed image in axial view: A: aneurysm, m: proximal modified Blalock Tausig shunt, a: aortic arch

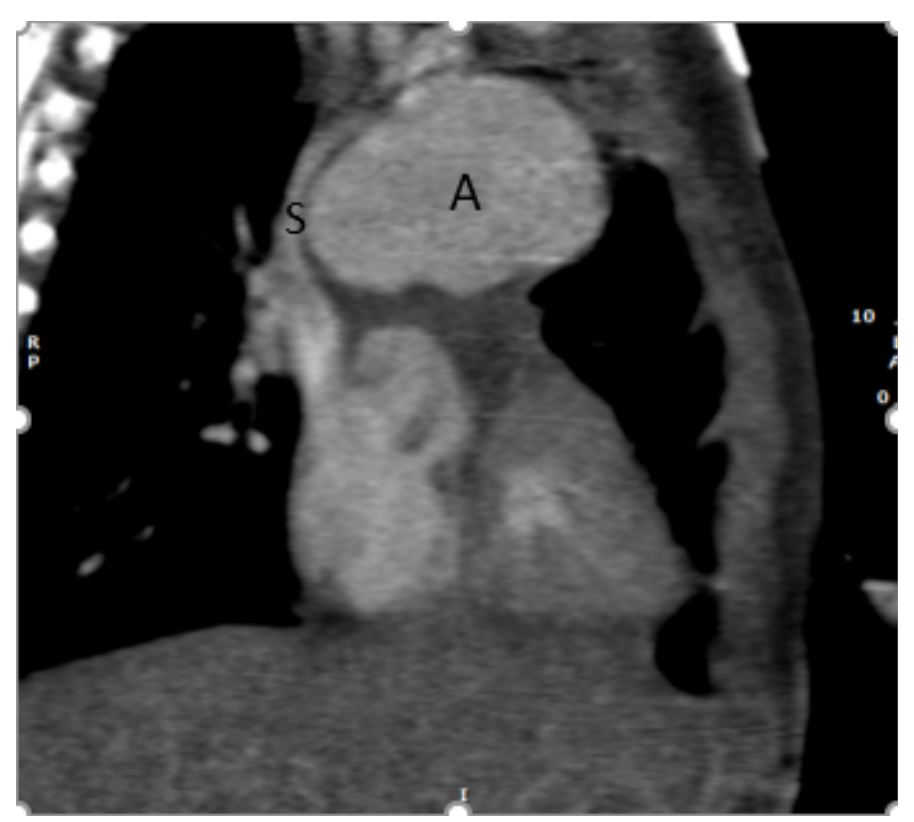

Figure 1B. Cardiac CT reconstructed image in coronal view: A: aneurysm, S: superior vena cava

${ }^{\star}$ Correspondence to: Dilachew Adebo, Department of Pediatrics, Division of Pediatric Cardiology, University of Texas Medical School at Houston, 6410 Fannin Street, Suite 425, Houston, Texas 77030, USA, Tel: 001773627 9497, E-mail: Dilachew.A.Adebo@uth.tmc.edu

Key words: pseudoaneurysm, modified blalock-taussig shunt, cardiac computed tomography

Received: September 02, 2020; Accepted: September 11, 2020; Published: September 18, 2020 


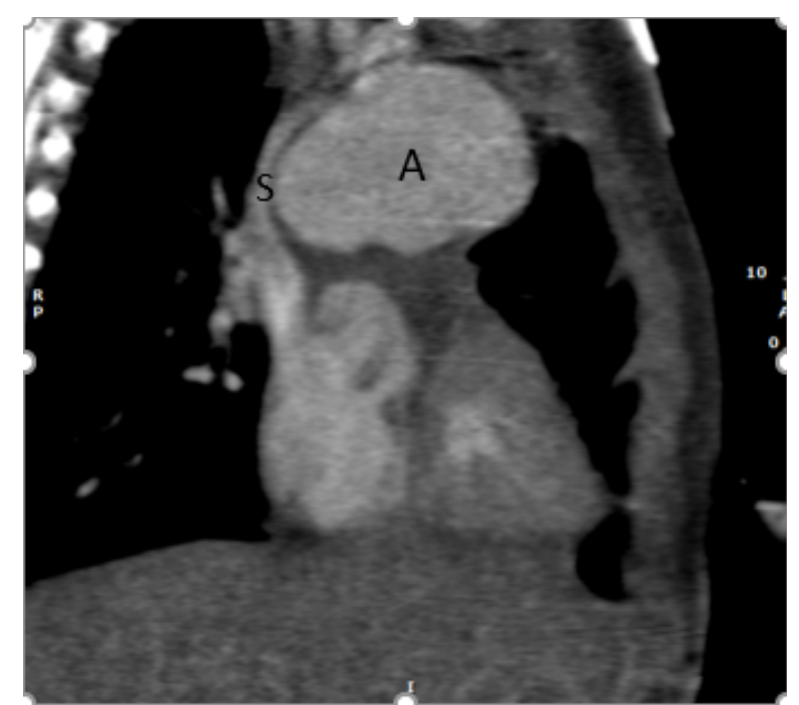

Figure 2A. Cardiac CT reconstructed image in coronal view showing distal modified Blalock Tausig shunt: BT: modified Blalock Taussig shunt, R: Right pulmonary artery

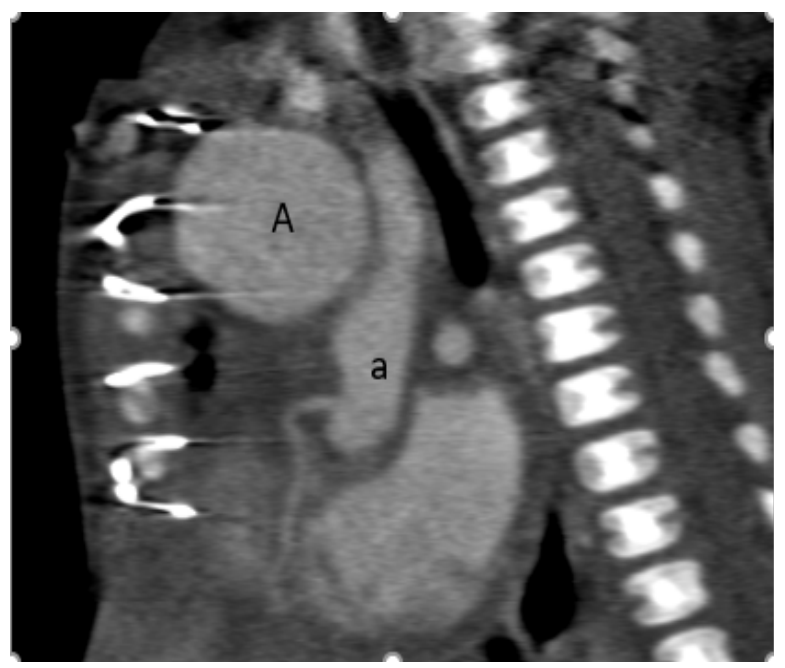

Figure 2B. Cardiac CT reconstructed image in sagittal view showing aneurysm and native aortic root with coronary artery: A: Aneurysm, a: Native aortic root

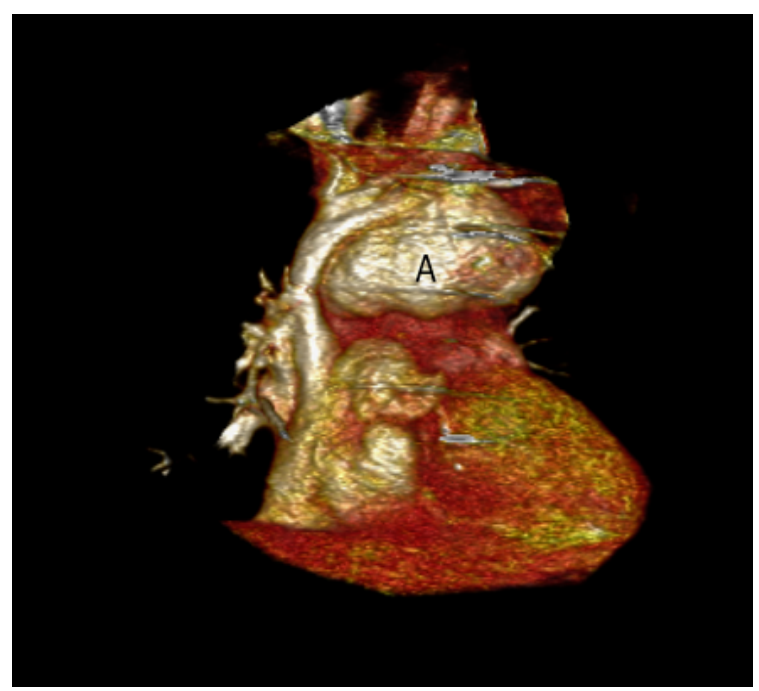

Figure 3A. Cardiac CT Volume rendered reconstruction: Anterior view: A: Aneurysm

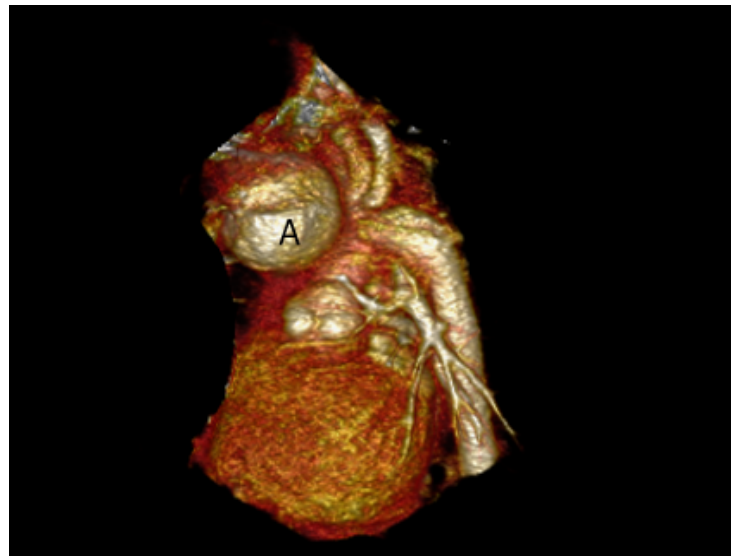

Figure 3B. Cardiac CT Volume rendered reconstruction: Lateral view: A: Aneurysm

\section{Discussion}

Modified BT shunt is commonly performed as the first palliative surgery in single ventricle physiology. Known complications of the modified BT shunt include excessive shunt flow, thrombosis, and pseudoaneurysm [2]. These complications are often managed by emergent surgical intervention with high rates of mortality and morbidity [3]. Here we report very unusual case of giant pseudoaneurysm which arises from insertion site of the shunt diagnosed by Cardiac CT. The patient was managed conservatively and subsequently underwent palliative surgery with good results.

\section{Acknowledgement}

The authors are grateful to the staff of the Cardiovascular computed tomography unit at Children's Memorial Hermann Hospital for their support in this work.

\section{Financial Support}

This research received no specific grant from any funding agency, commercial or non-for-profit sectors.

\section{Conflict of interest}

We know of no conflicts of interest associated with this publication and there has been no financial support for this work that could have influenced its outcome.

\section{Ethical Standard}

According to Children's Memorial Hermann Hospital Institutional Review Board, this case report was exempt from IRB approval process.

\section{References}

1. Parvathy U, Balakrishnan KR, Ranjith MS, Moorthy JS (2002) False aneurysm following modified Blalock-Taussig shunt. Pediatr Cardiol 23: 178-181. [Crossref]

2. Zaki SA, Shanbag P (2010) Pseudoaneurysm following modified Blalock Taussig shunt. Indian Pediatr 47: 198-199. [Crossref]

3. Baspinar O, Sahin DA, Sulu A, Gokaslan G (2016) Interventions Involving the Use of Covered Coronary Artery Stents for Pseudoaneurysms of Blalock-Taussig Shunts. World J Pediatr Congenit Heart Surg 7: 494-497. [Crossref]

Copyright: (C2020 John S. This is an open-access article distributed under the terms of the Creative Commons Attribution License, which permits unrestricted use, distribution, and reproduction in any medium, provided the original author and source are credited. 